\title{
VORWORT DES HERAUSGEBERS
}

Im Jahre I929 wurde Julius Beloch vom Tode überrascht, während er mit einer letzten Durchsicht seiner aus langjährigen Archiv-Nachforschungen hervorgegangenen und fast druckfertigen Arbeit über die Bevölkerungsgeschichte Italiens beschäftigt war.

Das Werk sollte das erste Glied einer Bevölkerungsgeschichte Europas sein, von welcher schon mehr oder weniger ausgearbeitete Manuskripte über die Bevölkerungsgeschichte Deutschlands, Frankreichs und Englands, ebenfalls auf die sorgfältigsten Archiv-Untersuchungen gegründet, vorliegen. Es umfaBt I2 Abschnitte:

I. Grundlagen. - II. Sizilien. - III. Königreich Neapel. - IV. Der Kirchenstaat. - V. Toscana. - VI. Die Herzogtümer am Po. - VII. Republik Venedig. - VIII. Das Herzogtum Mailand. - IX. Piemont. - X. Genova; Corsica. - XI. Sardinien. - XII. Gesamtbevölkerung

von denen die drei ersten in dem vorliegenden Bande enthalten sind.

Der Band, dessen Beendigung den Verfasser selbst nur noch wenige Monate oder gar Wochen beschäftigt hätte, erscheint jetzt verspätet durch mancherlei Ursachen, deren Aufzählung sich hier erübrigt. Sie waren alle unabhängig von dem Willen dessen, der für die Drucklegung Sorge getragen hat. Denn nachdem ich im Einverständnis mit den Töchtern meines tiefbetrauerten Lehrers diesen Auftrag übernommen hatte, war mein Bestreben, die Ausgabe dem von Beloch hinterlassenen Text und den Absichten des Verfassers so treu entsprechend wie nur möglich zu gestalten. Es wurde nichts Neues oder Persönliches in den Text eingefügt. Ich habe mich lediglich darauf beschränkt, bei zwei 
verschiedenen Fassungen desselben Inhalts diejenige auszuwählen, die mir den Absichten des Verfassers am meisten zu entsprechen schien, und einige Wiederholungen zu streichen. Die Berechnungen, insbesondere die der Prozente, sind, wie es auch der Verfasser gewünscht hatte, einer nochmaligen sorgfältigen Prüfung unterzogen worden.

In bezug auf die Provinzen des Königreichs Italien ist die Einteilung beibehalten worden, welche seit Begründung des Königreichs bis I925 gültig war, wie es der Verfasser selbst für angebracht hielt, da die seither vorgenommenen Veränderungen eine Umgestaltung erfordert hätten, die der Ubersicht der Entwicklung der Bevölkerung Italiens keine größere Deutlichkeit verliehen haben würde; im Gegenteil ist vielleicht der Überblick klarer bei Beibehaltung der traditionellen Umgrenzungen der Gebiete.

Ich gebe mich der Hoffnung hin, daB das Werk, dessen erster Teil hier erscheint, so herauskommt, wie es der Verfasser selbst gewünscht hätte. Gewiß sind die zu überwindenden Schwierigkeiten, die sich aus der mühseligen Lesbarkeit des italienischen sowohl als des deutschen Manuskriptes und aus der besonderen Erschwerung für mich durch ein dauerndes Augenleiden ergaben, keine geringen gewesen. Möge nun das Buch bei deutschen und italienischen Gelehrten eine günstige Aufnahme finden, und möge es beitragen und anregen zu jener kulturellen Zusammenarbeit zweier großer Nationen, für die Beloch sein ganzes Leben lang gewirkt hat.

Rom, den 27. Oktober 1936. Gaetano De Sanctis. 